Article

3

\title{
Trilactic Glyceride Benefits Intestinal Function of
} Weaned Piglets

\author{
Tao Wu ${ }^{1,+}$, Kang Li ${ }^{1,+}$, Yang Lyu ${ }^{1,2,+}$, Dan Yi ${ }^{1}$, Di Zhao ${ }^{1}$, Lei Wang ${ }^{1}$, Binying Ding ${ }^{1}$, Yongqing \\ Hou ${ }^{1, *}$, Guoyao Wu ${ }^{1,3}$ \\ 1 Hubei Key Laboratory of Animal Nutrition and Feed Science, Engineering Research Centre of Feed \\ Protein Resources on Agricultural By-products, Ministry of Education, Wuhan Polytechnic University, \\ Wuhan 430023, China; wutao@whpu.edu.cn (T.W.); lee49127@163.com (K.L.); yidan810204@whpu.edu.cn \\ (D.Y.); zhaodi@whpu.edu.cn (D.Z.); wanglei@whpu.edu.cn (L.W.); dbying7471@126.com (B.D.) \\ 2 Department of Nutrition, Genetics and Ethology, Faculty of Veterinary Medicine, Ghent University, 9820 \\ Merelbeke, Belgium; yang.lyu@ugent.be (Y.L.) \\ 3 Department of Animal Science, Texas A\&M University, TX77843, USA; g-wu@tamu.edu (G.W.) \\ + These authors equally contributed to this work \\ * Correspondence: houyq@whpu.edu.cn (Y.H.); Tel: +86-27-83956227
}

\begin{abstract}
Both lactic acid and short chain fatty acid (SCFA) play important roles in maintenance of intestinal epithelial structure and function. Trilactic glyceride (TLG) obtains both excellences of lactic acid and SCFA. This study was to investigate the effects of trilactic glyceride on growth performance, blood parameters, liver function, intestinal morphology and intestine function of piglets. Twelve weaned piglets $(21 \pm 2 \mathrm{~d})$ were randomly allocated to two treatment groups: 1 ) control group, piglets fed the basal diet; 2) TLG group, piglets fed the basal diet supplemented with $0.5 \%$ TLG. On day 21 of the trial, D-xylose $(0.1 \mathrm{~g} / \mathrm{kg} \cdot \mathrm{BW})$ was orally administrated to all piglets and blood samples were collected $1 \mathrm{~h}$ thereafter. Then, all the piglets were sacrificed to examine intestinal mucosal morphology and collect fatty tissue, liver and intestinal mucosa for further analysis. The results showed that: compared with the control group, TLG group decreased blood ALB and GGT on day 10 and 20, TLG group decreased blood TP and increased blood TG on day 20 of the trail ( $\mathrm{p}<0.05)$; TLG group decreased blood D-xylose and LDL, increased blood HDL $(\mathrm{p}<$ $0.05)$. These data suggested that supplementing trilactic glyceride had beneficial impacts on promoting nutrients' metabolism, maintaining intestinal integrity, and alleviating oxidative stress and diarrhoea. Further research of molecular mechanisms showed changing expression levels of related proteins and genes, suggesting that these could be involved in the regulation of the impact. The community composition of the gut microbiota was also found to be altered in several operational taxonomic units within the genus, Prevotella (order Bacteroidales), and the order, Clostridiales.
\end{abstract}

Keywords: Trilactic glyceride; Intestinal function; Gut microbiota; Weaned piglet

\section{Introduction}

Short chain triglyceride (SCT) is formed by short chain fatty acid (SCFA) and glyceryl ester, which play an extremely important role in maintenance of morphological structure and intestinal epithelial function [1,2]. It can be absorbed by intestinal fast as energy storage, reduce the osmotic pressure of intestinal tract and boost absorption of $\mathrm{Na}+$ [3]. Recent researches indicated that SCFA can adjust the $\mathrm{pH}$ of the gastrointestinal tract and alleviate the injury of intestinal barrier for the weaning stress, inhibit the growth of harmful bacteria and promote the growth of probiotics, regulate the immune system activity at the same time [4,5]. Moreover, SCFA are mainly produced by the microorganism's fermentation of sugar in the colon and cecum except for the additive of SCFA in animal food, which could not be digested and absorbed by the intestines of animals [6]. 
It is widely considered that lactic acid has remarkable beneficial effect on the growth and production of animals especially the young animals [7]. Lactic acid is largely used as a growth promoter in animal feed, which is highly active and able to activate digestive enzyme, improve digestion of amino acid and development of intestinal epithelium, and inhibit growth of microbe especially E. coli and Salmonella [8-10]. Several studies have demonstrated that the addition of lactic acid to the diet of poultry and piglets can effectively inhibit the growth of pathogenic bacteria and increase the speed of animal weight gain [11,12]. Unfortunately, it is too hard to arrive intestinal tract and play its function, which might be destroyed when added into the animal food directly [13]. Therefore, the outside source of lactic acid in the gut was primarily obtained by lactic acid production probiotics, more and more studies of lactic acid have been frequently focused on lactate-forming materials [14].

As one kind of short chain triglyceride, trilactic glyceride (TLG) could decompose into lactic acid and glyceryl ester in the digestive tract, which means it obtains both excellences of lactate and SCFA. Several authors have reported many positive changes of chicken fed diets supplemented with trilactic glyceride, which was involved in production performance, anti-oxidative capacity and energy metabolism $[15,16]$.

However, there are still highly limited evidences suggesting whether or how trilactic glyceride could affect growth performance and intestinal function in weaned piglets. The objective of this study was to determine how trilactic glyceride used in diets with improving growth performance and liver and intestine function in weaned piglets.

\section{Results and Discussion}

\subsection{Growth performance}

Growth performance is a major criterion used to evaluate outcomes of animal production. There was not significant difference in average daily feed intake (ADFI) and gain (ADG) as well as ratio of feed and gain $(\mathrm{F} / \mathrm{G})$ between control and TLG group. However, dietary supplementation with $0.5 \%$ TLG substantially decreased diarrhoea rate (DR) during day 0 to 10 and day 0 to 20 (Table 1 ), this means that trilactic glyceride could effectively relieve diarrhoea in weaned piglets.

Table 1. The growth performance of piglets.

\begin{tabular}{ccccccc}
\hline \multirow{2}{*}{ Item } & \multicolumn{2}{c}{ Day 0 to day 10 } & \multicolumn{2}{c}{ Day 11 to day 21 } & \multicolumn{2}{c}{ Day 0 to day 21 } \\
\cline { 2 - 7 } & Control & TLG & Control & TLG & Control & TLG \\
\hline $\mathrm{ADG} / \mathrm{g}$ & $244.50 \pm 52.04$ & $235.50 \pm 80.06$ & $437.75 \pm 69.84$ & $411.50 \pm 73.03$ & $341.13 \pm 56.04$ & $323.50 \pm 69.82$ \\
$\mathrm{ADFI} / \mathrm{g}$ & $308.13 \pm 8.32$ & $321.38 \pm 66.11$ & $662.29 \pm 86.14$ & $658.06 \pm 43.31$ & $485.21 \pm 44.06$ & $489.72 \pm 51.60$ \\
$\mathrm{~F} / \mathrm{G}$ & $1.28 \pm 0.19$ & $1.39 \pm 0.16$ & $1.52 \pm 0.10$ & $1.61 \pm 0.11$ & $1.43 \pm 0.09$ & $1.52 \pm 0.11$ \\
$\mathrm{DR} / \%$ & $15.00 \pm 10.69^{\mathrm{b}}$ & $8.75 \pm 11.26^{\mathrm{a}}$ & $2.50 \pm 4.63$ & $3.75 \pm 10.61$ & $8.33 \pm 6.61^{\mathrm{b}}$ & $5.95 \pm 8.73^{\mathrm{a}}$ \\
\hline
\end{tabular}

Values are means $\pm S D, n=6$. ${ }^{\text {a }}$ b Means within rows with different superscripts differ $(P<0.05)$.

\subsection{Haematological indexes}

All measured haematological indexes in piglets are listed in Table 2. The results showed that TLG group enjoyed a rise in the concentration of TG (day 20) and BUN as well as the number of white blood cells, and it experienced a drop in the concentration of ALB, CHOL (day 10) and GGT. Except for these indexes, others were not obviously affected by TLG including blood cell compositions and blood biochemical indexes. Some changes involved with blood cell compositions and biochemical indexes occurred after TLG supplementation, but they were still within normal limits [17]. This result showed that trilactic glyceride has inconspicuous impact on haematological indexes. 
Table 2. Blood biochemical indices of piglets.

\begin{tabular}{ccccc}
\hline \multirow{2}{*}{ Item } & \multicolumn{2}{c}{ Sampling on day 10 } & \multicolumn{2}{c}{ Sampling on day 10 } \\
\cline { 2 - 5 } & Control & TH & Control & TH \\
\hline ALB $(\mathrm{g} / \mathrm{L})$ & $30.26 \pm 2.45^{\mathrm{b}}$ & $27.58 \pm 2.45^{\mathrm{a}}$ & $30.16 \pm 1.77^{\mathrm{b}}$ & $27.46 \pm 2.53^{\mathrm{a}}$ \\
CHOL (mmol/L) & $1.82 \pm 0.26^{\mathrm{b}}$ & $1.64 \pm 0.15^{\mathrm{a}}$ & $1.83 \pm 0.10$ & $1.95 \pm 0.20$ \\
TG (mmol/L) & $0.40 \pm 0.10$ & $0.43 \pm 0.14$ & $0.48 \pm 0.10^{\mathrm{a}}$ & $0.63 \pm 0.15^{\mathrm{b}}$ \\
BUN (mmol/L) & $3.10 \pm 1.04^{\mathrm{a}}$ & $3.66 \pm 0.74^{\mathrm{b}}$ & $2.91 \pm 0.96^{\mathrm{a}}$ & $3.49 \pm 0.76^{\mathrm{b}}$ \\
GGT (mmol/L) & $35.05 \pm 5.21^{\mathrm{b}}$ & $29.10 \pm 6.10^{\mathrm{a}}$ & $30.44 \pm 4.00^{\mathrm{b}}$ & $26.89 \pm 2.48^{\mathrm{a}}$ \\
WBC (109/L) & $14.91 \pm 3.53^{\mathrm{a}}$ & $17.46 \pm 5.36^{\mathrm{b}}$ & $14.18 \pm 3.16^{\mathrm{a}}$ & $17.78 \pm 2.79^{\mathrm{b}}$ \\
LDL (mmol/L) & - & - & $0.92 \pm 0.12^{\mathrm{a}}$ & $0.81 \pm 0.09^{\mathrm{b}}$ \\
HDL (mmol/L) & - & - & $0.38 \pm 0.10^{\mathrm{a}}$ & $0.61 \pm 0.12^{\mathrm{b}}$ \\
D-xylose $(\mu \mathrm{mol} / \mathrm{L})$ & - & - & $0.391 \pm 0.129^{\mathrm{a}}$ & $0.624 \pm 0.115^{\mathrm{b}}$ \\
\hline
\end{tabular}

\subsection{Glycogen and fat metabolism}

Values are means $\pm \mathrm{SD}, \mathrm{n}=6$. a, $\mathrm{b}$ Means within rows with different superscripts $\operatorname{differ}(P<0.05)$.

Intervention trials and prospective studies have shown that hypercholesterolemia, especially increased concentrations of LDL cholesterol, leads to the development of atherosclerosis [18,19]. In contrast, prospective studies have demonstrated a negative correlation between plasma HDL cholesterol and cardiovascular disease [20]. The content of plasma low density lipoprotein (LDL) in TLG group significantly decreased while the high-density lipoprotein (HDL) increased relative to control group (Table 2). The result about LDL and HDL of this research reflected that trilactic glyceride could effectively lower cholesterol and reduce fat deposition.

Table 3. Relative expression levels of genes associated with glycogen metabolism.

\begin{tabular}{ccccccccc}
\hline \multirow{2}{*}{ Item } & \multicolumn{2}{c}{ Duodenum } & \multicolumn{2}{c}{ Jejunum } & \multicolumn{2}{c}{ Ileum } & \multicolumn{2}{c}{ Colon } \\
\cline { 2 - 9 } & Control & TH & Control & TH & Control & TH & Control & TH \\
\hline INSR & $1.00 \pm 0.21^{\mathrm{a}}$ & $1.49 \pm 0.38^{\mathrm{b}}$ & $1.00 \pm 0.19^{\mathrm{a}}$ & $1.08 \pm 0.25^{\mathrm{a}}$ & $1.00 \pm 0.17$ & $1.06 \pm 0.19$ & $1.00 \pm 0.24$ & $1.08 \pm 0.16$ \\
$P C K 1$ & $1.00 \pm 0.24^{\mathrm{a}}$ & $2.08 \pm 0.39^{\mathrm{b}}$ & $1.00 \pm 0.22^{\mathrm{a}}$ & $1.39 \pm 0.28^{\mathrm{b}}$ & $1.00 \pm 0.16^{\mathrm{a}}$ & $2.38 \pm 0.63^{\mathrm{b}}$ & $1.00 \pm 0.29^{\mathrm{a}}$ & $1.59 \pm 0.35^{\mathrm{b}}$ \\
$A S S 1$ & $1.00 \pm 0.27^{\mathrm{b}}$ & $0.65 \pm 0.13^{\mathrm{a}}$ & $1.00 \pm 0.26$ & $0.81 \pm 0.16$ & $1.00 \pm 0.18^{\mathrm{b}}$ & $0.81 \pm 0.18^{\mathrm{a}}$ & $1.00 \pm 0.27^{\mathrm{b}}$ & $0.70 \pm 0.17^{\mathrm{a}}$ \\
\hline \multicolumn{3}{c}{ Values are means $\pm \mathrm{SD}, \mathrm{n}=6 .^{\mathrm{a}, \mathrm{b}}$ Means within rows with different superscripts differ $(P<0.05)}$.
\end{tabular}

\section{9}

The insulin receptor (INSR) is a transmembrane receptor that is activated by insulin, IGF-I, IGF-II and belongs to the large class of tyrosine kinase receptors [21]. Binding of insulin or other ligands to this receptor activates the insulin signalling pathway, which regulates glucose uptake and release, as well as the synthesis and storage of carbohydrates, lipids and protein [22]. Phosphoenolpyruvate carboxykinase 1 (PCK1) is a main control point for the regulation of gluconeogenesis, which can be regulated by insulin, glucocorticoids, glucagon, cAMP, and diet [23]. The protein encoded by gene argininosuccinate synthase 1 (ASS1) catalyses the penultimate step of the arginine biosynthetic pathway, which facilitates pyrimidine synthesis in cancerous proliferation by activating CAD, through regulation of aspartate levels [24,25]. In this study, supplementation with TLG remarkably increased expression levels of INSR in duodenum and PCK1 in four bowels, decreased expression levels of ASS1 in four bowels (Table 3). The result suggested that trilactic glyceride could effectively improve the capacity of glycogenesis and glycogenolysis, could positively regulate glycometabolism of weaned piglets.

Hormone sensitive lipase (lipase E, LIPE) is one kind of lipases, which perform essential roles in the digestion, transport and processing of dietary lipids such as triglycerides, fats and oils in most living organisms [26]. The main function of LIPE is to mobilize the stored fats [27]. Lipoprotein lipase (LPL) is expressed in heart, muscle, and adipose tissue, which functions as a homodimer, obtains the double functions of triglyceride hydrolase and ligand/bridging factor for 
117

118

119

120

121

122

123

124

125

126

127

128

129

130

131

132

133

134

135

136

137

\subsection{Intestinal morphology and function}

\begin{tabular}{ccccccc}
\hline \multirow{2}{*}{ Item } & \multicolumn{2}{c}{ Fat } & \multicolumn{2}{c}{ Liver } & \multicolumn{2}{c}{ Jejunum } \\
\cline { 2 - 7 } & Control & TH & Control & TH & Control & TH \\
\hline LIPE & $1.00 \pm 0.17$ & $1.23 \pm 0.24$ & $1.00 \pm 0.23^{\mathrm{b}}$ & $0.68 \pm 0.13^{\mathrm{a}}$ & $1.00 \pm 0.22$ & $0.97 \pm 0.18$ \\
$L P L$ & $1.00 \pm 0.27$ & $0.86 \pm 0.23$ & $1.00 \pm 0.19^{\mathrm{b}}$ & $0.57 \pm 0.15^{\mathrm{a}}$ & $1.00 \pm 0.20^{\mathrm{b}}$ & $0.66 \pm 0.12^{\mathrm{a}}$ \\
$P P A R G$ & $1.00 \pm 0.25$ & $1.07 \pm 0.24$ & $1.00 \pm 0.18$ & $0.94 \pm 0.16$ & $1.00 \pm 0.24$ & $0.95 \pm 0.18$ \\
$A C A C A$ & $1.00 \pm 0.22$ & $1.27 \pm 0.31$ & $1.00 \pm 0.09$ & $1.11 \pm 0.15$ & $1.00 \pm 0.15$ & $1.00 \pm 0.12$ \\
$F A S N$ & $1.00 \pm 0.19^{\mathrm{a}}$ & $1.42 \pm 0.29^{\mathrm{b}}$ & $1.00 \pm 0.26^{\mathrm{b}}$ & $0.64 \pm 0.16^{\mathrm{a}}$ & $1.00 \pm 0.23^{\mathrm{b}}$ & $0.75 \pm 0.14^{\mathrm{a}}$ \\
$S L C 27 A 2$ & $1.00 \pm 0.27^{\mathrm{a}}$ & $2.06 \pm 0.52^{\mathrm{b}}$ & $1.00 \pm 0.23^{\mathrm{b}}$ & $0.61 \pm 0.14^{\mathrm{a}}$ & $1.00 \pm 0.22$ & $0.97 \pm 0.13$ \\
\hline \multicolumn{2}{c}{ Values are means $\pm \mathrm{SD}, \mathrm{n}=6 .^{\mathrm{a}, \mathrm{b}}$ Means within rows with different superscripts differ $(P<0.05)}$.
\end{tabular}

The indicators of the small-intestinal morphology are villus height, crypt depth, the ratio of villus height to crypt depth, and villous surface area [37]. Usually, an increase in villus height, villous surface area, or villus/crypt ratio corresponds to improvement in intestinal absorption capacity and health [38]. However, the data of this research showed that supplementation with trilactic glyceride rised the crypt depth and declined villus width as well as the ratio of villus height to crypt depth in jejunum (Table 5), this condition might involve with its particular acidity, anti-inflammation effect or potential physiological toxicity.

Table 5. Intestinal morphology indexes of piglets.

\begin{tabular}{ccccc}
\hline \multirow{2}{*}{ Item } & \multicolumn{2}{c}{ Jejunum } & \multicolumn{2}{c}{ Ileum } \\
\cline { 2 - 5 } & Control & TH & Control & TH \\
\hline Villus height $(\mu \mathrm{m})$ & $262.25 \pm 12.53$ & $262.01 \pm 28.73$ & $259.63 \pm 23.47$ & $263.90 \pm 38.61$ \\
Crypt depth $(\mu \mathrm{m})$ & $60.35 \pm 3.72^{\mathrm{a}}$ & $77.46 \pm 10.94^{\mathrm{b}}$ & $66.01 \pm 9.92$ & $64.11 \pm 9.08$ \\
Ratio of villus height to crypt depth & $4.35 \pm 0.23^{\mathrm{b}}$ & $3.42 \pm 0.39^{\mathrm{a}}$ & $3.97 \pm 0.33$ & $4.13 \pm 0.34$ \\
Villus surface area $\left(\mu \mathrm{m}^{2}\right)$ & $121.08 \pm 7.66^{\mathrm{b}}$ & $98.41 \pm 13.70^{\mathrm{a}}$ & $103.83 \pm 12.81$ & $110.35 \pm 12.69$ \\
\hline Values are means $\pm \mathrm{SD}, \mathrm{n}=6$ 6. $^{\mathrm{a}, \mathrm{b}}$ Means within rows with different superscripts differ $(P<0.05)$.
\end{tabular}


Table 6. Relative expression levels of genes associated with intestinal function.

\begin{tabular}{ccccccccc}
\hline \multirow{2}{*}{ Item } & \multicolumn{2}{c}{ Duodenum } & \multicolumn{2}{c}{ Jejunum } & \multicolumn{2}{c}{ Ileum } & \multicolumn{2}{c}{ Colon } \\
\cline { 2 - 9 } & Control & TH & Control & TH & Control & TH & Control & TH \\
\hline INSR & $1.00 \pm 0.21^{\mathrm{a}}$ & $1.49 \pm 0.38^{\mathrm{b}}$ & $1.00 \pm 0.19^{\mathrm{a}}$ & $1.08 \pm 0.25^{\mathrm{a}}$ & $1.00 \pm 0.17$ & $1.06 \pm 0.19$ & $1.00 \pm 0.24$ & $1.08 \pm 0.16$ \\
$P C K 1$ & $1.00 \pm 0.24^{\mathrm{a}}$ & $2.08 \pm 0.39^{\mathrm{b}}$ & $1.00 \pm 0.22^{\mathrm{a}}$ & $1.39 \pm 0.28^{\mathrm{b}}$ & $1.00 \pm 0.16^{\mathrm{a}}$ & $2.38 \pm 0.63^{\mathrm{b}}$ & $1.00 \pm 0.29^{\mathrm{a}}$ & $1.59 \pm 0.35^{\mathrm{b}}$ \\
$A S S 1$ & $1.00 \pm 0.27^{\mathrm{b}}$ & $0.65 \pm 0.13^{\mathrm{a}}$ & $1.00 \pm 0.26$ & $0.81 \pm 0.16$ & $1.00 \pm 0.18^{\mathrm{b}}$ & $0.81 \pm 0.18^{\mathrm{a}}$ & $1.00 \pm 0.27^{\mathrm{b}}$ & $0.70 \pm 0.17^{\mathrm{a}}$ \\
$A Q P 8$ & $1.00 \pm 0.25$ & $1.18 \pm 0.28$ & $1.00 \pm 0.22^{\mathrm{a}}$ & $1.32 \pm 0.28^{\mathrm{b}}$ & $1.00 \pm 0.24^{\mathrm{a}}$ & $1.82 \pm 0.45^{\mathrm{b}}$ & $1.00 \pm 0.26^{\mathrm{a}}$ & $1.87 \pm 0.42^{\mathrm{b}}$ \\
$A Q P 10$ & $1.00 \pm 0.17^{\mathrm{a}}$ & $1.89 \pm 0.47^{\mathrm{b}}$ & $1.00 \pm 0.23^{\mathrm{a}}$ & $1.49 \pm 0.31^{\mathrm{b}}$ & $1.00 \pm 0.21$ & $1.06 \pm 0.25$ & $1.00 \pm 0.24$ & $1.22 \pm 0.26$ \\
Nrf2 & $1.00 \pm 0.19$ & $0.92 \pm 0.21$ & $1.00 \pm 0.23^{\mathrm{a}}$ & $1.65 \pm 0.44^{\mathrm{b}}$ & $1.00 \pm 0.13^{\mathrm{b}}$ & $0.77 \pm 0.12^{\mathrm{a}}$ & $1.00 \pm 0.23^{\mathrm{a}}$ & $1.31 \pm 0.29^{\mathrm{b}}$ \\
NOX2 & $1.00 \pm 0.20^{\mathrm{b}}$ & $0.76 \pm 0.17^{\mathrm{a}}$ & $1.00 \pm 0.22^{\mathrm{b}}$ & $0.68 \pm 0.14^{\mathrm{a}}$ & $1.00 \pm 0.14^{\mathrm{b}}$ & $0.67 \pm 0.13^{\mathrm{a}}$ & $1.00 \pm 0.13^{\mathrm{b}}$ & $0.81 \pm 0.14^{\mathrm{a}}$ \\
GSTO2 & $1.00 \pm 0.23^{\mathrm{a}}$ & $6.75 \pm 1.13^{\mathrm{b}}$ & $1.00 \pm 0.23^{\mathrm{a}}$ & $5.63 \pm 1.14^{\mathrm{b}}$ & $1.00 \pm 0.19^{\mathrm{a}}$ & $1.53 \pm 0.25^{\mathrm{b}}$ & $1.00 \pm 0.25^{\mathrm{a}}$ & $7.27 \pm 1.16^{\mathrm{b}}$ \\
\hline
\end{tabular}

Absorption of D-xylose from the intestinal lumen into plasma is a useful marker of in vivo intestinal function in animals [39]. Generally, one-hour blood D-xylose test is used to measure intestinal absorption capacity and mucosal integrity [38]. In this study, the activities of plasma D-xylose in TLG group had approximately over twice times as many as that in control group (Table 2 ), reflected that trilactic glyceride could dramatically improve intestinal absorptive capacity of piglets.

Values are means $\pm S D, n=6$. ${ }^{a}, b$ Means within rows with different superscripts differ $(P<0.05)$.

Aquaporin-8 and 10 (AQP8 and AQP10) are two of the most important water channel protein that regulation the water homeostasis in the central nervous system, which remain with the aquaporin family of integral membrane proteins that conduct water in and out the cell [40]. All function of them is to afford fast water transport as well as support self-balanced within the CNS [41]. The data of this study showed that TLG group experienced a noticeably growth in the expression levels of AQP8 and AQP10 (Table 6), indicated that trilactic glyceride could substantially improve intestinal capacity of water transfer and absorption.

Nuclear factor like 2 (Nrf2) is a basic leucine zipper (bZIP) protein that regulates the expression of antioxidant proteins that protect against oxidative damage triggered by injury and inflammation [42]. Several drugs that stimulate the Nrf2 pathway are being studied for treatment of diseases that are caused by oxidative stress [43]. NOX2 is one member of the NADPH oxidase family, which generates superoxide by transferring electrons from NADPH inside the cell across the membrane and coupling these to molecular oxygen to produce superoxide anion, a reactive free-radical [44]. Glutathione S-transferase omega-2 (GSTO2) participates in detoxification of inorganic arsenic, catalyses the reduction of monomethylarsonic acid to monomethylarsonous acid, the rate limiting step in detoxification of inorganic arsenic. Over expression of GSTO2 indicated apoptosis [45]. In this research, supplementation with TLG significantly increased the expression levels of Nrf2 in jejunum and colon as well as NOX2 and GSTO2 in four bowels (Table 6), these results suggested that trilactic glyceride could effectively activate antioxidant enzymes and particularly improve intestinal antioxidant capacity.

Intestinal epithelial integrity is maintained by cohesive interactions between cells via the formation of tight junctions [46]. Claudin-1 and occludin integrate such diverse processes as gene transcription, tumour suppression, and cell proliferation to modulate intestinal-mucosal structure and function [47]. Villin is one kind of actin binding protein and a marker of villus cell differentiation $[48,49]$, which conduce to prop up the microfilaments of the microvilli of the mucosal villus. HSP70 proteins protect cells from thermal or oxidative stress, a high concentration of HSP70 is indicative of oxidative stress (Rhoads and Wu 2009). Caspase-3 is commonly activated by numerous "death" signals to cleave a variety of important cellular proteins. This protein is either partially or totally responsible for the proteolytic cleavage of many key "death" proteins [50]. The data of this study showed that TLG group enjoyed a remarkable growth in the protein expression levels of claudin-1 and occludin (Figure 1) and an obvious drop in that of villin, HSP70 and caspase-3 (Figure 
188

189

190

191

192

193

194

195

196

197

198

199

200

201

202

203

204

205

206

207

208

209

210

211

212

213

214

215

216

217

218

219
2), these results supported that trilactic glyceride could protect intestinal mucosa from injuries, exert beneficial effects on epithelial barrier as well as cell growth and survival.

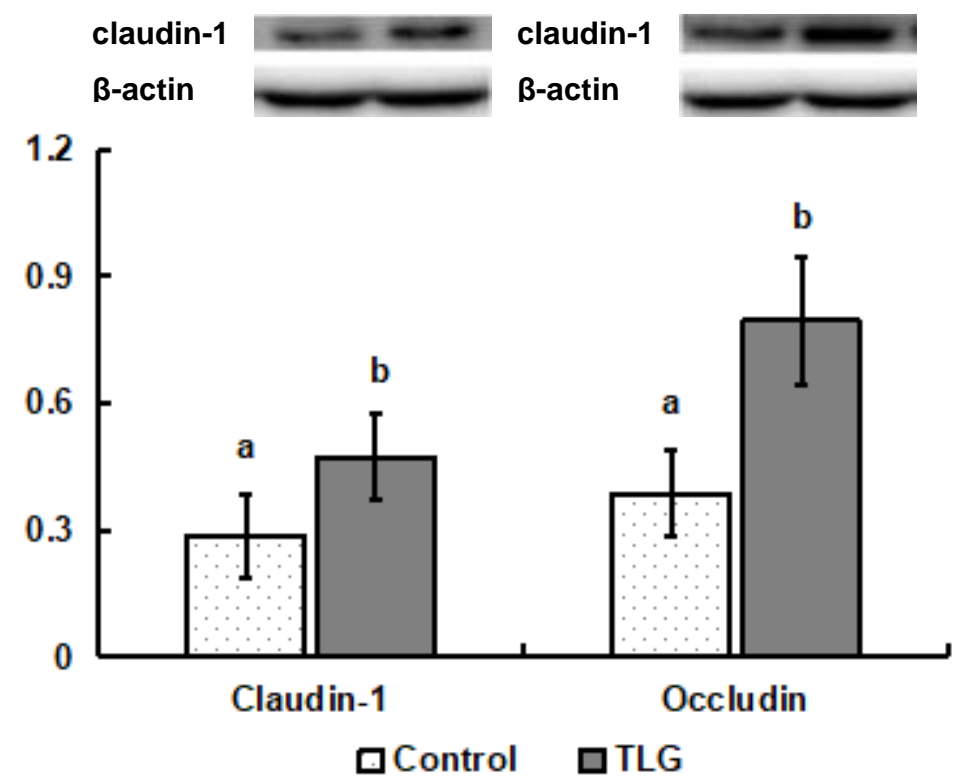

Figure 1. Protein expression levels of claudin-1 and occludin

Values are means $\pm \mathrm{SD}, \mathrm{n}=6$. ${ }^{\mathrm{a}, \mathrm{b}}$ Different letters differ significant $(P<0.05)$.

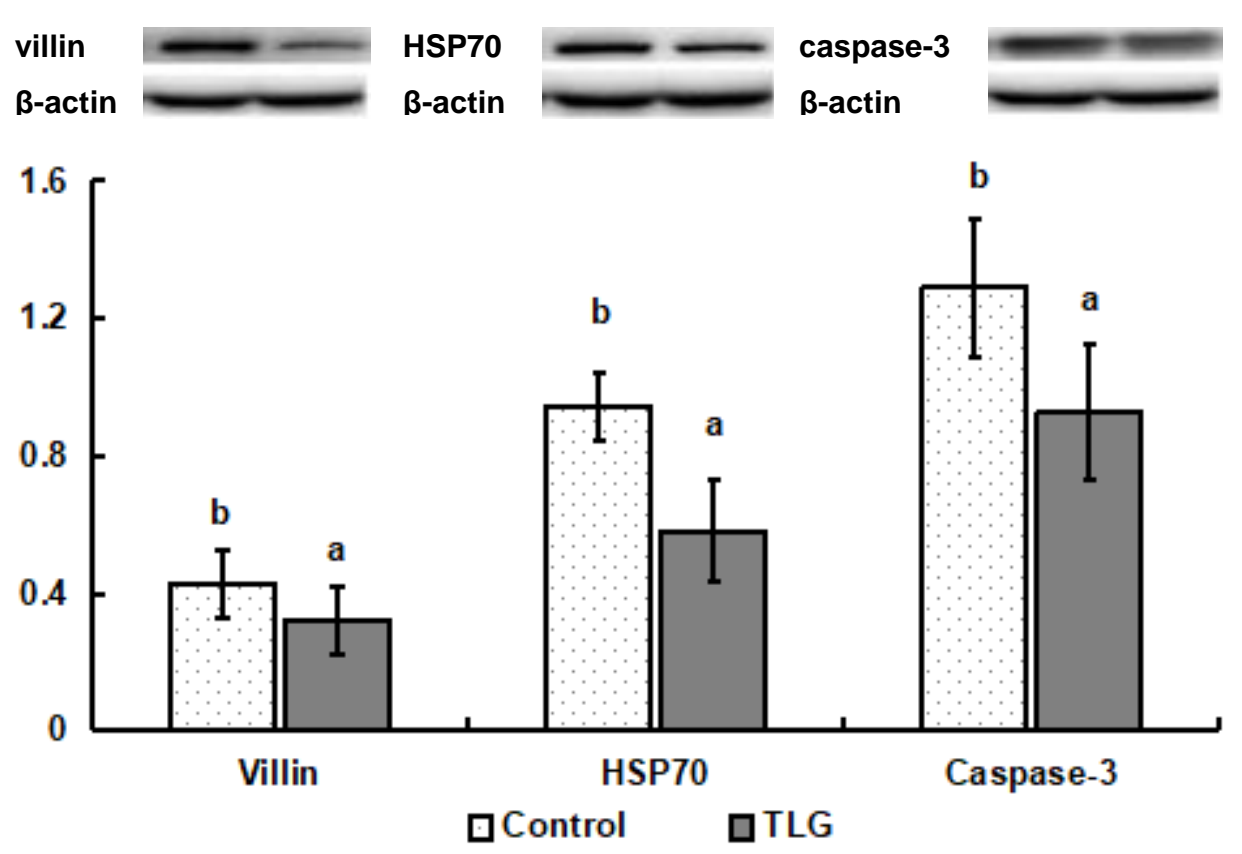

Figure 2. Protein expression levels of villin, HSP70 and caspase-3

Values are means $\pm \mathrm{SD}, \mathrm{n}=6{ }^{\mathrm{a}, \mathrm{b}}$ Different letters differ significant $(P<0.05)$.

\subsection{Gut Microbiota}

The diversity analysis of the gut microbiota in the ileum, colon, and cecum are shown in Figure 3. There was a significant difference in the Shannon $\alpha$-diversity index between the control group $(6.43 \pm 0.27)$ and the TLG group $(6.20 \pm 0.35)$ in the colon $(p=0.194)$, but no difference in the ileum and cecum. There was a significant difference in the $\beta$-diversity (weighted Unifrac) between the 
control and the TLG group in the ileum $(p=0.149)$ and between the control and the TLG group in the colon $(p=0.132)$, but no difference in the cecum.

A total of 844,095 reads were obtained from the ileum in the two groups, with 406,358 reads from the control group and 437,737 from the TLG group. A total of 992,078 reads were obtained from the colon, with 501,510 reads from the control group and 490,568 from the TLG group. A total of $1,995,806$ reads were obtained from the cecum, with 906,235 reads from the control group and $1,089,571$ from the TLG group. The relative abundance of the OTUs (Operational Taxonomic Units) is summarized in Table 6 . There were 6 OTUs with a significant difference in the ileum, 17 significant OTUs in the colon, and 15 significant OTUs in the cecum.

The mean relative abundances of the different predominant taxa at phylum and genus level in the community composition of each group are shown in Figure $4(a, b)$. The dominant bacteria at the phylum level were Firmicutes and Proteobacteria in the ileum, and Bacteroidetes and Firmicutes in the colon and cecum. The dominant bacteria at the genus level were Turicibacter, Clostridiales. f. g, Clostridiaceae. g, and Enterobacteriaceae. $\mathrm{g}$ in the ileum, and Prevotella in the colon and cecum.
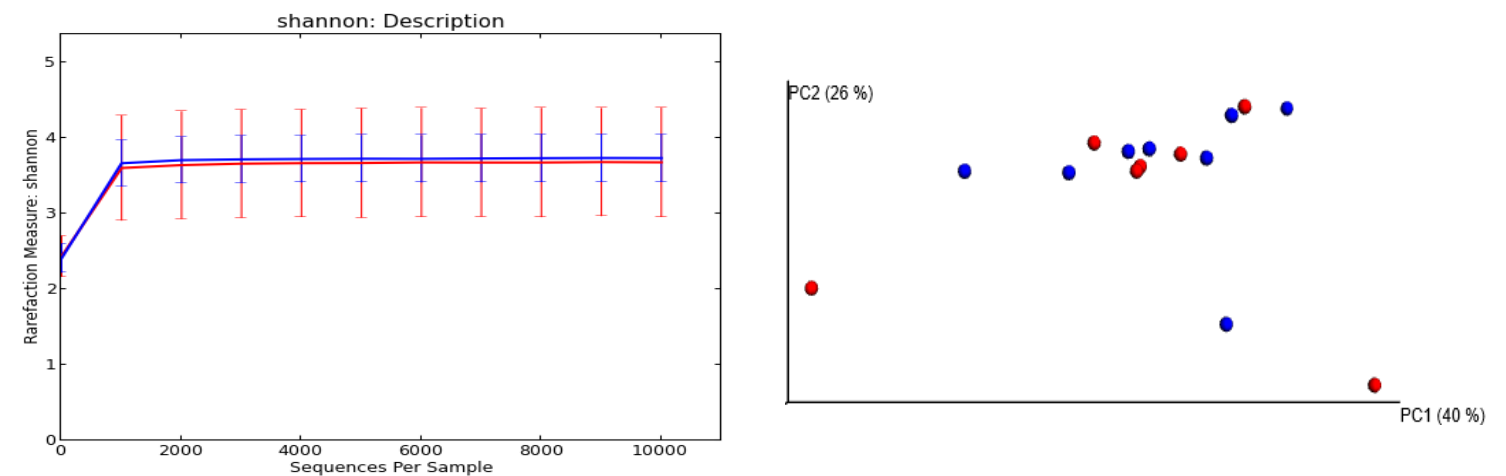

Ileum
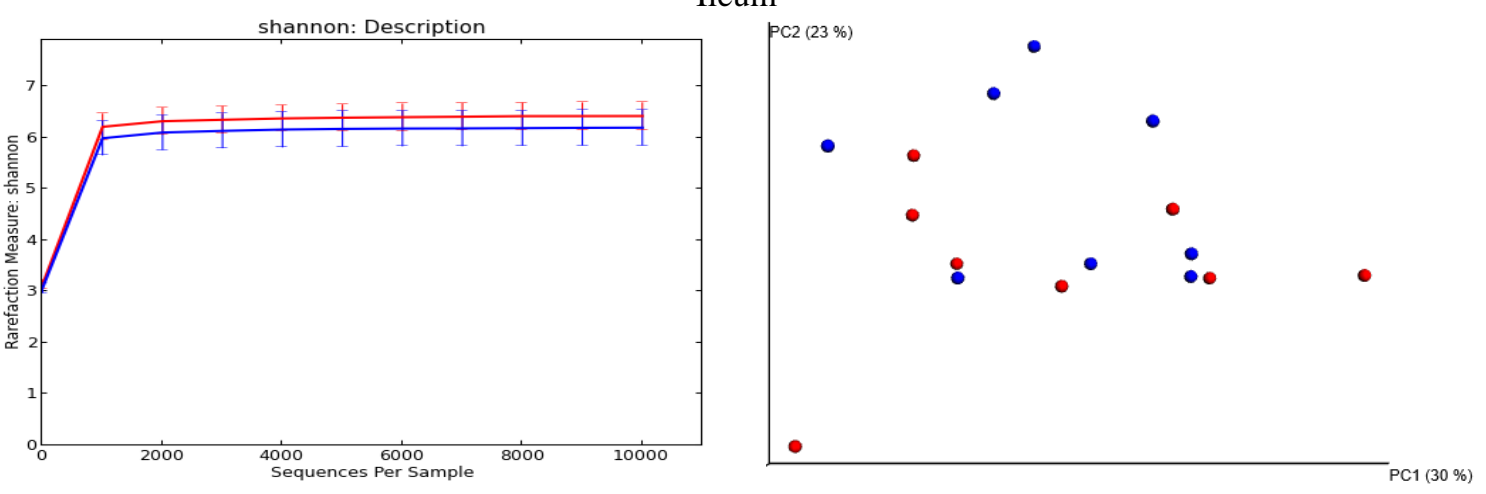

Colon
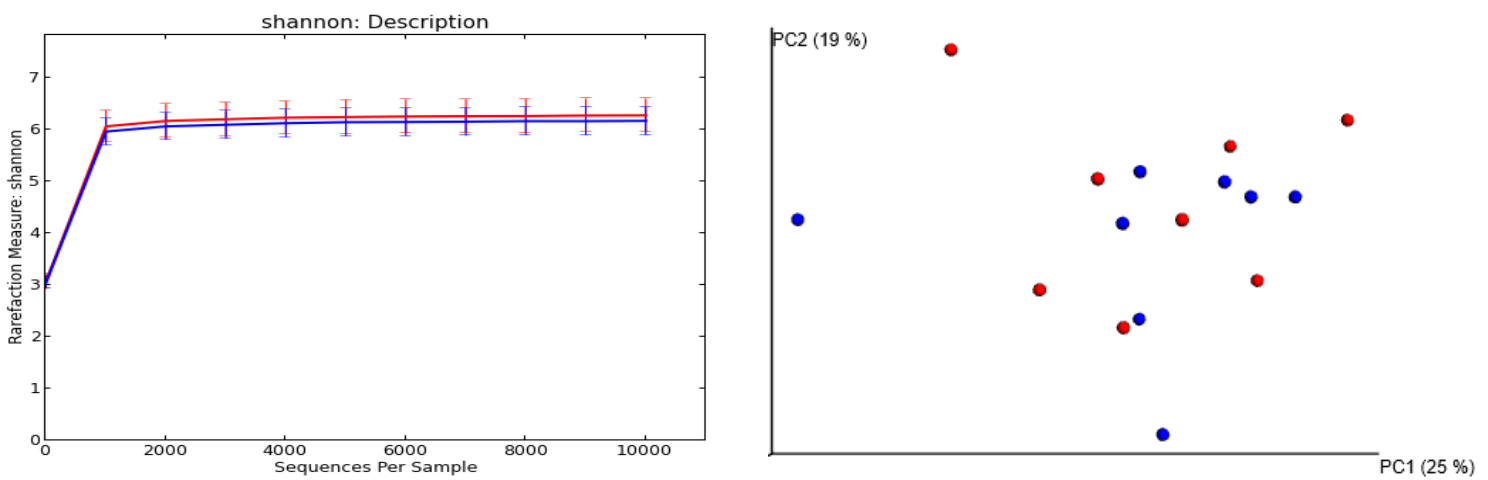

Cecum Control group TLG group

Fig. 3. The Shannon $\alpha$-diversity index (rarefaction curves) and $\beta$-diversity (weighted UniFrac principal component analysis). 
Table 7. Relative abundance of the operational taxonomic units (OTUs).

\begin{tabular}{|c|c|c|c|c|c|}
\hline \multirow{2}{*}{ OTU } & \multirow{2}{*}{$p$ Value } & \multirow{2}{*}{$\begin{array}{c}\text { FDR } \\
p \text { Value }\end{array}$} & \multicolumn{2}{|c|}{ Relative Abundance } & \multirow{2}{*}{ Taxonomy } \\
\hline & & & $\mathrm{C}$ & TLG & \\
\hline \multicolumn{6}{|c|}{ Ileum } \\
\hline 108729 & 0.005 & 0.902 & 17.571 & 0.125 & o_Pasteurellales; f_Pasteurellaceae; $\mathrm{g}$ _Actinobacillus \\
\hline 524213 & 0.015 & 0.902 & 3.286 & 0.125 & o_Bacteroidales; f_Paraprevotellaceae; g_Prevotella \\
\hline 4397402 & 0.017 & 0.902 & 3.571 & 0.000 & o_Lactobacillales; f_Lactobacillaceae; g_Lactobacillus \\
\hline OTU13 & 0.036 & 0.902 & 4.714 & 0.250 & o_Pasteurellales; f_Pasteurellaceae; g_Actinobacillus \\
\hline OTU78 & 0.047 & 0.902 & 3.286 & 0.000 & o_Clostridiales; f_Clostridiaceae; $\mathrm{g}_{-}$ \\
\hline 471412 & 0.047 & 0.902 & 11.714 & 0.000 & o_Pasteurellales; $\mathrm{f}_{-}$Pasteurellaceae; $\mathrm{g}_{-}$ \\
\hline \multicolumn{6}{|c|}{ Colon } \\
\hline 300859 & 0.001 & 0.512 & 63.125 & 14.375 & o_Bacteroidales; f_Prevotellaceae; g_Prevotella \\
\hline 265871 & 0.003 & 0.512 & 27 & 1.875 & o_Clostridiales; f_Ruminococcaceae; g_Faecalibacterium \\
\hline OTU93 & 0.004 & 0.512 & 0.25 & 94.875 & o_Bacteroidales; $\mathrm{f}$ PPrevotellaceae; $\mathrm{g}$ _Prevotella \\
\hline 275237 & 0.006 & 0.512 & 311 & 161.125 & o_Clostridiales; f_Veillonellaceae; g_Phascolarctobacterium \\
\hline 515074 & 0.006 & 0.512 & 167.75 & 592.75 & o_Bacteroidales; f_Paraprevotellaceae; g_Prevotella \\
\hline 181056 & 0.009 & 0.512 & 67.75 & 10.875 & o_Clostridiales; $\mathrm{f} \_$Ruminococcaceae; $\mathrm{g}$ Faecalibacterium \\
\hline 279534 & 0.011 & 0.512 & 37.25 & 0 & o_Clostridiales; $\mathrm{f}_{-}$Ruminococcaceae; $\mathrm{g}_{-}$ \\
\hline 524213 & 0.012 & 0.512 & 73.625 & 250.875 & o_Bacteroidales; f_Paraprevotellaceae; g_Prevotella \\
\hline 76393 & 0.013 & 0.512 & 269.125 & 16.375 & o_Bacteroidales; $\mathrm{f}$ _Prevotellaceae; $\mathrm{g}$ _Prevotella \\
\hline 254846 & 0.018 & 0.542 & 78.375 & 11.125 & o_Clostridiales; f_Lachnospiraceae; $\mathrm{g}_{-}$ \\
\hline 4341056 & 0.021 & 0.542 & 64.875 & 6.25 & o_Clostridiales; f_Lachnospiraceae; $\mathrm{g}_{-}$ \\
\hline 354254 & 0.027 & 0.561 & 19.125 & 0 & o_Clostridiales; f_Lachnospiraceae; g_Coprococcus \\
\hline 16915 & 0.027 & 0.561 & 0 & 54.875 & o_Bacteroidales; f_p-2534-18B5; g_ \\
\hline 176705 & 0.036 & 0.561 & 167.25 & 56.75 & o_Clostridiales; f_Veillonellaceae; g_Phascolarctobacterium \\
\hline 322999 & 0.040 & 0.561 & 13 & 2.375 & o_Clostridiales; f_Ruminococcaceae; $\mathrm{g}$ \\
\hline 299382 & 0.046 & 0.561 & 18.75 & 0.5 & o_Bacteroidales; f_Prevotellaceae; g_Prevotella \\
\hline OTU56 & 0.046 & 0.561 & 19 & 0.625 & $\mathrm{o}_{-} Y S 2 ; \mathrm{f}_{-} ; \mathrm{g}_{-}$ \\
\hline \multicolumn{6}{|c|}{ Cecum } \\
\hline 254846 & 0.001 & 0.399 & 73.5 & 2.75 & o_Clostridiales; $\mathrm{f}_{-} L a c h n o s p i r a c e a e ; \mathrm{g}_{-}$ \\
\hline 254376 & 0.002 & 0.399 & 23.375 & 0.625 & o_Clostridiales; f_Lachnospiraceae; g_Roseburia \\
\hline 515074 & 0.005 & 0.562 & 215.25 & 593.25 & o_Bacteroidales; $\mathrm{f}$ _Paraprevotellaceae; $\mathrm{g}_{\text {_Prevotella }}$ \\
\hline OTU95 & 0.009 & 0.606 & 0.125 & 52.125 & o_Bacteroidales; $\mathrm{f}$ _Prevotellaceae; $\mathrm{g}$ _Prevotella \\
\hline 4341056 & 0.010 & 0.606 & 47.75 & 1.125 & o_Clostridiales; f_Lachnospiraceae; $\mathrm{g}_{\text {_ }}$ \\
\hline 295861 & 0.018 & 0.660 & 4.125 & 16.125 & o_Clostridiales; f_; $\mathrm{g}_{-}$ \\
\hline 531046 & 0.021 & 0.660 & 86 & 11.875 & o_Bacteroidales; $\mathrm{f}$ _Prevotellaceae; $\mathrm{g}$ _Prevotella \\
\hline 163857 & 0.027 & 0.660 & 179.375 & 38.125 & o_Aeromonadales; f_Succinivibrionaceae; g_Succinivibrio \\
\hline OTU2 & 0.033 & 0.660 & 0.875 & 11 & o_Bacteroidales; f_Prevotellaceae; g_Prevotella \\
\hline 608244 & 0.034 & 0.660 & 2.375 & 19.75 & o_Clostridiales; $\mathrm{f} \_$Ruminococcaceae; $\mathrm{g}$ _Ruminococcus \\
\hline 300859 & 0.040 & 0.660 & 54.125 & 24.375 & o_Bacteroidales; f_Prevotellaceae; g_Prevotella \\
\hline 4410166 & 0.040 & 0.660 & 54.75 & 16.875 & o_Bacteroidales; f_Prevotellaceae; g_Prevotella \\
\hline 25461 & 0.043 & 0.660 & 4 & 42.125 & o_Clostridiales; f_Ruminococcaceae; $\mathrm{g}_{-}$ \\
\hline 193191 & 0.043 & 0.660 & 12 & 1.875 & o_Clostridiales; f_Lachnospiraceae; g_Lachnospira \\
\hline 169515 & 0.045 & 0.660 & 27.875 & 10.625 & $\mathrm{o} \_$Clostridiales; $\mathrm{f}_{-} ; \mathrm{g}_{-}$ \\
\hline
\end{tabular}

In the gut microbiota of mammals, Firmicutes and Bacteroidetes were the dominant phyla, followed by Fusobacteria, Proteobacteria, and Actinobacteria [51]. Previous studies have also presented the similar result that Firmicutes and Bacteroidetes were still the main phyla in pigs regardless of the growing ages or different intestinal segments [52]. Despite the variations showed in Figure $4(a, b)$ only 38 OTUs underwent statistically significant changes among the groups (Table 7) and most of them belong to the genus Prevotella, or are included in the order, Clostridiales, specifically in two of its families (Lachnospiraceae and Ruminocccaceae), and a very close one (Veillonellaceae). Prevotella tend to colonize animals and the human gut, and may cause infections, but can also co-exist harmlessly with their human host [53]. It is increasingly gaining attention as a commensal microbe in the intestine because of its ability to degrade a broad spectrum of plant polysaccharides [54]. The Veillonellaceae family are mainly bacteria related to the metabolism of nutrients, especially the metabolism of amino acids [55]. The Lachnospiraceae and Ruminococcaceae families are common gut microbes that break down complex carbohydrates, and they are most common in the digestive tracts of animals with carb-heavy diets. This is usually good for ruminants, which have a great difference to pigs [56,57]. In this study, the composition of some OTUs belonging to Prevotella, Lachnospiraceae, Veillonellaceae and 
283 Ruminococcaceae had significant differences, indicating that supplementing trilactic glyceride could

284 benefit and optimize the digestion and absorption of nutrients, thus, reducing anyt unnecessary 285 waste of nutrients.

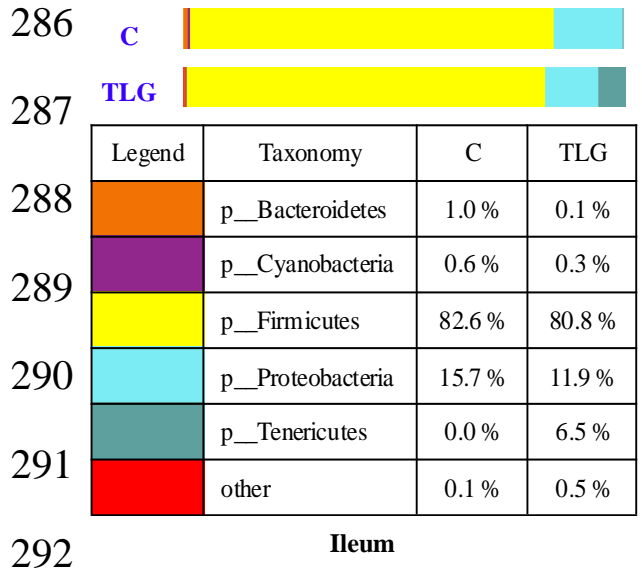

(a

293

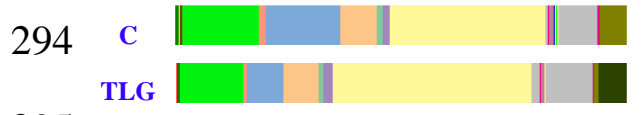

\begin{tabular}{|c|c|c|c|}
\hline Legend & Taxonomy & $\mathrm{C}$ & TLG \\
\hline 206 & g__Prevotella & $0.7 \%$ & $0.1 \%$ \\
\hline & o_Streptophyta;f_; & $0.6 \%$ & $0.3 \%$ \\
\hline 297 & g__Lactobacillus & $16.8 \%$ & $14.1 \%$ \\
\hline & g__Streptococcus & $1.7 \%$ & $0.6 \%$ \\
\hline (e & g__Turicibacter & $16.3 \%$ & $8.1 \%$ \\
\hline 299 & o_Clostridiales;other & $9.4 \%$ & $9.0 \%$ \\
\hline & g__Clostridium & $0.5 \%$ & $1.0 \%$ \\
\hline 300 & g__SMB53 & $0.3 \%$ & $0.2 \%$ \\
\hline & f_Clostridiaceae;other & $0.1 \%$ & $0.3 \%$ \\
\hline 301 & f_Clostridiaceae; & $34.4 \%$ & $44.0 \%$ \\
\hline 302 & f_Peptostreptococcaceae;g_ & $0.9 \%$ & $0.7 \%$ \\
\hline & f_Enterobacteriaceae;g_ & $8.8 \%$ & $10.6 \%$ \\
\hline 303 & g__Klebsiella & $0.4 \%$ & $0.2 \%$ \\
\hline 304 & g__Actinobacillus & $6.0 \%$ & $1.0 \%$ \\
\hline & g__Mycoplasma & $0.0 \%$ & $6.5 \%$ \\
\hline & other & $1.6 \%$ & $0.5 \%$ \\
\hline
\end{tabular}
Ileum

(b

Figure 4. The community composition of gut microbiota.

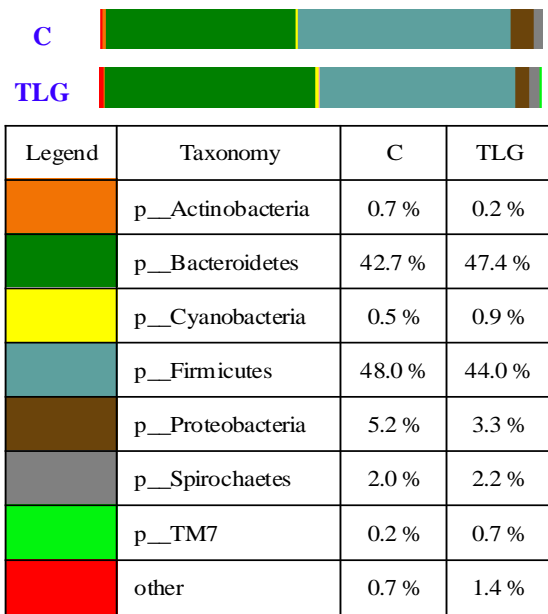

Colon

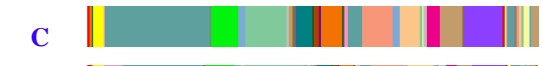
TLG |

\begin{tabular}{|c|c|c|c|}
\hline Legend & Taxonomy & $\mathrm{C}$ & TLG \\
\hline & o__Bacteroidales; $; \_\_; g_{-}$ & $2.3 \%$ & $2.2 \%$ \\
\hline & g__Parabacteroides & $0.3 \%$ & $4.3 \%$ \\
\hline & g__Prevotella & $23.2 \%$ & $18.0 \%$ \\
\hline & f__S24-7;g_- & $6.0 \%$ & $6.4 \%$ \\
\hline & g__CF231 & $1.4 \%$ & $1.4 \%$ \\
\hline & g__Prevotella & $9.0 \%$ & $13.4 \%$ \\
\hline & o__YS2;f_;g_- & $0.5 \%$ & $0.9 \%$ \\
\hline & g__Lactobacillus & $0.9 \%$ & $0.7 \%$ \\
\hline & o__Clostridiales;f_;g_ & $3.6 \%$ & $3.4 \%$ \\
\hline & f_Clostridiaceae; g_ & $1.1 \%$ & $1.1 \%$ \\
\hline & f_LLachnospiraceae;g__ & $4.9 \%$ & $3.3 \%$ \\
\hline & g__Roseburia & $3.2 \%$ & $2.3 \%$ \\
\hline & f_Ruminococcaceae;g__ & $6.8 \%$ & $7.6 \%$ \\
\hline & g__Faecalibacterium & $1.3 \%$ & $0.3 \%$ \\
\hline & g__oscillospira & $4.5 \%$ & $5.7 \%$ \\
\hline & f_Veillonellaceae;other & $0.3 \%$ & $1.0 \%$ \\
\hline & g__Acidaminococcus & $0.7 \%$ & $1.2 \%$ \\
\hline & g__Anaerovibrio & $2.9 \%$ & $2.6 \%$ \\
\hline & g__Megasphaera & $4.9 \%$ & $3.2 \%$ \\
\hline & g__Phascolarctobacterium & $8.6 \%$ & $7.4 \%$ \\
\hline & o__Tremblayales;f_; & $1.7 \%$ & $1.2 \%$ \\
\hline & g_Actinobacillus & $1.2 \%$ & $0.0 \%$ \\
\hline & g__Treponema & $1.8 \%$ & $2.0 \%$ \\
\hline & other & $6.6 \%$ & $7.6 \%$ \\
\hline
\end{tabular}

Colon (a) phylum level; (b) genus level.

\begin{tabular}{|c|c|c|c|}
\hline \multirow[t]{9}{*}{ Legend } & Taxonomy & $\mathrm{C}$ & TLG \\
\hline & p__Actinobacteria & $0.2 \%$ & $0.2 \%$ \\
\hline & p__Bacteroidetes & $42.8 \%$ & $40.2 \%$ \\
\hline & p__Cyanobacteria & $1.2 \%$ & $2.2 \%$ \\
\hline & p__Firmicutes & $49.0 \%$ & $50.3 \%$ \\
\hline & p__Proteobacteria & $4.6 \%$ & $3.3 \%$ \\
\hline & p__Spirochaetes & $1.3 \%$ & $2.3 \%$ \\
\hline & p__TM7 & $0.1 \%$ & $0.3 \%$ \\
\hline & other & $0.7 \%$ & $1.1 \%$ \\
\hline
\end{tabular}

Cecum
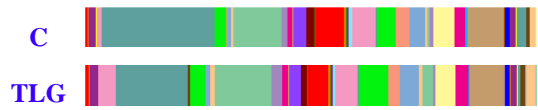

\begin{tabular}{|c|c|c|c|}
\hline \multirow[t]{3}{*}{ Legend } & Taxonomy & $\mathrm{C}$ & TLG \\
\hline & o__Bacteroidales;f_;g__ & $1.5 \%$ & $1.8 \%$ \\
\hline & g__Parabacteroides & $1.1 \%$ & $3.8 \%$ \\
\hline & g__Prevotella & $24.8 \%$ & $15.8 \%$ \\
\hline & f_S $24-7 ; g$ & $2.7 \%$ & $3.4 \%$ \\
\hline & g__YRC22 & $0.4 \%$ & $1.1 \%$ \\
\hline & g__Prevotella & $10.8 \%$ & $12.6 \%$ \\
\hline & o__YS2;f__g__- & $1.2 \%$ & $1.2 \%$ \\
\hline & g__Lactobacillus & $0.9 \%$ & $1.4 \%$ \\
\hline & o__Clostridiales;f_;g__ & $2.9 \%$ & $2.6 \%$ \\
\hline & f__Clostridiaceae;g___ & $1.6 \%$ & $1.3 \%$ \\
\hline & f_LLachnospiraceae;g__ & $6.6 \%$ & $4.6 \%$ \\
\hline & g__Roseburia & $5.2 \%$ & $5.1 \%$ \\
\hline & f__Ruminococcaceae;g__ & $4.2 \%$ & $6.4 \%$ \\
\hline & g__Faecalibacterium & $3.2 \%$ & $2.5 \%$ \\
\hline & g__Oscillospira & $3.3 \%$ & $4.2 \%$ \\
\hline & f__Veillonellaceae;g__ & $1.5 \%$ & $3.2 \%$ \\
\hline & g__Anaerovibrio & $4.9 \%$ & $4.4 \%$ \\
\hline & g__Megasphaera & $2.3 \%$ & $2.9 \%$ \\
\hline & g__Phascolarctobacterium & $8.0 \%$ & $7.5 \%$ \\
\hline & g__p-75-a5 & $0.8 \%$ & $1.1 \%$ \\
\hline & o__Tremblayales;f__;g__ & $1.4 \%$ & $1.2 \%$ \\
\hline & g__Succinivibrio & $1.9 \%$ & $0.4 \%$ \\
\hline & f__Enterobacteriaceae;g_ & $0.8 \%$ & $1.0 \%$ \\
\hline & g__Treponema & $1.3 \%$ & $2.2 \%$ \\
\hline & other & $5.4 \%$ & $6.3 \%$ \\
\hline
\end{tabular}

Cecum 


\section{Materials and Methods}

313

314

315

316

317

318

319

320

321

322

323

\subsection{Experimental Design and Sample Collection}

The animal use protocol for this research was approved by the Animal Care and Use Committee of Hubei Province (protocol code: WH2018-0604). Twelve crossbred healthy piglets (Duroc $\times$ Landrace $\times$ Yorkshire) were weaned at 21 days of age. After weaning, piglets had free access to the basal diet between days 21 and 24 of age (days $0-3$ postweaning) for adapting to solid foods. At 24 days of age, piglets $(7.25 \pm 1.13 \mathrm{~kg}$ body weight) were assigned randomly into one of the two treatment groups: (1) control group, piglets fed the basal diet; (2) TLG group, piglets fed the basal diet supplemented with $0.5 \%$ trilactic glyceride (TLG). Each piglet was individually housed in a $1.20 \times 1.10 \mathrm{~m} 2$ steel metabolic cage with eight replicate cages per treatment. All diets were isocaloric [17]. On day 20 of the trial, $1 \mathrm{~h}$ after infusion of D-xylose [58], blood, liver and intestine samples were collected and stored at $-80^{\circ} \mathrm{C}$ until assay [59].

\subsection{Plasma Biochemical Indicators}

Blood biochemical parameters were assessed using an automatic analyser (7020 Clinical Analyzer, Hitachi High-Technologies Company). D-xylose, LDL and HDL in the plasma and liver lipid contents were analysed using commercially available kits (Jiancheng Bioengineering Institute, Nanjing, China) [37]. Assays were carried out in triplicate.

\subsection{Intestinal Morphology}

Tissue samples used for the morphometric study were dehydrated and embedded in paraffin, sectioned at a thickness of $4 \mathrm{~mm}$, and stained with haematoxylin and eosin. Morphological measurements were carried out with a light microscope (American Optical Company). Intestinal villus height and width, as well as crypt depth and villous surface area were measured using a linear ocular micrometer equipped with a computer-assisted morphometric system (BioScan Optimetric Inc., Edmonds, WA, U.S.A.) [38].

\subsection{Expression Levels of Genes}

The gene expression levels in liver and intestine samples were quantitated by the method of real-time PCR [60]. The real-time PCR was carried out with primers designed to span introns and intron-exon boundaries (Table 8) and was performed using the SYBR $®$ Premix Ex TaqTM (Takara, Dalian, China) on 7500 Fast Real-Time PCR System (Foster City, CA, U.S.A.). Data was analysed by the 2- $\Delta \mathrm{Ct}$ method [61]. Each biological sample was run in triplicate.

\subsection{Expression Levels of Proteins}

The protein expression levels were performed by western blotting (24). The primary antibodies: AQP3, AQP4, and caspase-3 (rabbit, 1:1000; Cell Signalling Technology, Inc., MA, U,S,A,), occludin and villin (mouse, 1:1000; Sant Cruze Biotechnology, CA, U.S.A.), HSP70 and claudin-1 (mouse, 1:1000; Invitrogen, CA, U.S.A.), $\beta$-actin (mouse, 1:2000; Sigma-Aldrich Inc., St. Louis, USA). The secondary antibody: anti-rabbit (mouse, 1:2000; Zhongshan Golden Bridge Biological Technology Co., Beijing, China) and anti-mouse (rabbit, 1:2000; Invitrogen, CA, U.S.A.). Blots were carried out by utilising a chemiluminescence kit (Amersham Biosciences, Uppsala, Sweden) and an image forming system (Alpha Innotech, CA, U.S.A.) [62].

\subsection{Analysis of Gut Microbiota}

Total bacterial DNA was extracted, the gene-specific sequences targeted the $16 \mathrm{~S}$ V3 and V4 regions and were amplified with two stage PCR, and then were analysed by MiSeq sequencing. The results were processed with QIIME as described by Caporaso et al. [63].

$\alpha$-Diversity metrics were calculated using a read depth of 10,000 and a $\beta$-diversity distance matrix was calculated based on the UniFrac metric, which was used for the principal coordinate's 
357

358

359

360

361

362

363

364

365

analysis [64]. The significance of the diet effect on the $\beta$-diversity distance matrix was assessed by PERMANOVA analysis [64]. Raw sequence data and detection and removal of chimeras were performed using the software, USEARCH and UCHIIME [63,65].

\subsection{Statistical Analysis}

Data were analysed using a one-way analysis of variance to analysis, expressed as mean values \pm SEM. All experimental data was analysed using SPSS (Version 17.0, SPSS Inc., Chicago, IL, USA). A $p$-value of $<0.05$ was considered statistically significant. The data of the gut microbiota were processed by QIIME platform.

Table 8. Sequences of the primers used for quantitative RT-PCR analysis.

\begin{tabular}{|c|c|c|}
\hline Genes & Forward Sequences & Reverse Sequences \\
\hline$A Q P 8$ & TGTGTCTGGAGCCTGCATGAAT & AGCAGGAATCCCACCATCTCA \\
\hline$A Q P 10$ & TGTCTGCTTTCTGTGCCTCTG & GGATGCCATTGCTCAAGGATAGATAA \\
\hline$N r f 2$ & GAAGTGATCCCCTGATGTTGC & ATGCСТTСТСТTTССССТАТTTCT \\
\hline NOX2 & TGTATCTGTGTGAGAGGCTGGTG & CGGGACGCTTGACGAAA \\
\hline GSTO2 & GCCTTGAGATGTGGGAGAGAA & AAGATGGTGTTCTGATAGCCAAGA \\
\hline INSR & GGGGCTAAAGAGGAACTATGAGG & AGAGGAAAGCGAAGACAGGAAA \\
\hline PCK1 & CGGGATTTCGTGGAGA & ССТСТTGATGACACССТСТ \\
\hline ASS1 & СССТСАСТTТGСССАТСТСТ & СССТАСССТTCCGTTTGCT \\
\hline LIPE & CCAGCCCTGCCTTAATGTG & TCCCGAATACCCGCAAAG \\
\hline PPARG & AGGACTACCAAAGTGCCATCAAA & GAGGCTTTATCCCCACAGACAC \\
\hline$A C A C A$ & TGGCAGTGGTCTTCGTGTG & TCATCСАСАТССТТСАСАТААССТ \\
\hline FASN & ACACCTTCGTGCTGGCCTAC & ATGTCGGTGAACTGCTGCAC \\
\hline$L P L$ & AGCCTGAGTTGGACCCATGT & СTCTGTTTTCССTTCСTСTCTCC \\
\hline SLC27A2 & TTTTCAGCCAGCCACTTTTG & CATTTGGTTTCTGGGGAGAGTT \\
\hline RPL4 & GAGAAACCGTCGCCGAAT' & GCCCACCAGGAGCAAGTT \\
\hline GADPH & CGTCCCTGAGAGACACGATGGT & GCCTTGACTGYGCCGTGGAAT \\
\hline
\end{tabular}

\section{Conclusion}

Throughout the ages, researchers have devoted to adding various nutrient, probiotics and too many limits for researchers to design and decide nutrition administration, for example, incompatibility, interaction or antagonism. Particularly, lactic acid could be destroyed when SCFA was added into animal food, so that it was not active and able to function. Trilactic glyceride (TLG) could decompose into lactic acid and glyceryl ester in the digestive tract, which means it obtains both excellences of lactate and SCFA. This study was determined to research the impact of trilactic glyceride on weaned piglets, and there were three conclusions as follows: 1) trilactic glyceride supplementation could protect piglets from diarrhoea, which is one of the biggest problems in pig breeding industry; 2) trilactic glyceride could regulate glycogen and fat metabolism via improving the capacity of glycogenesis and glycogenolysis, promoting fat synthesis and exogenous fatty acids activation in adipose tissue and inhibiting fat synthesis and decomposition in liver and intestine; 3) trilactic glyceride could improve intestinal transfer, absorption and antioxidant capacity, benefit epithelial barrier as well as cell growth and survival via regulating 
expression levels of relevant gene and protein; 4) trilactic glyceride could benefit and optimize the digestion and absorption of nutrients, reducing anyt unnecessary waste of nutrients via regulating composition of gut microbiota. Finally, these results indicated that trilactic glyceride could be supplemented to animal food as a new probiotic.

Author Contributions: T.W. and Y.H. conceived and designed the experiments; K.L and Y.L. performed the experiments; Y.L., D.Z., L.W. and D.Y. analysed the data; B.D., G.W., and Y.H. contributed analysis tools and helped in the Results and Discussion Section; T.W. and Y.L. wrote this paper. All authors read and approved the manuscript.

Funding: This research was jointly supported by National Key R\&D Program of China (2017YFD0500505), Open Project of Hubei Key Laboratory of Animal Nutrition and Feed Science (201905), Program of National Agricultural Research Outstanding Talents of China (2015), Hubei Provincial Technology and Innovation Program (2017AHB062), Natural Science Foundation of Hubei Province (2016CFA070), the Hubei Hundred Talent Program, and Texas AgriLife Research (H-8200).

Conflicts of Interest: The authors declare that no conflict of interest.

\section{References}

1. Maggio, C.A.; Koopmans, H.S. Food intake after intragastric meals of short-, medium-, or long-chain triglyceride. Physiol. Behav. 1982, 28, 921-926.

2. Klemann, L.P.; Aji, K.;Chrysam, M.M.; Amelia, R.P.; Henderson, J.M.; Huang, A.S.; Otterburn, M.S.; Yarger, R.G. Random nature of triacylglycerols produced by the catalyzed interesterification of short- and long-chain fatty acid triglycerides. J. Agr. Food Chem. 1994, 42, 442.

3. López, S.; Hovell, F.D.; Macleod, N.A. Osmotic pressure, water kinetics and volatile fatty acid absorption in the rumen of sheep sustained by intragastric infusions. Br. J. Nutr. 1994, 71, 153.

4. Penner, G.B.; Aschenbach, J.R.; Wood, K.; Walpole, M.E.; Kanafany-Guzman, R.; Hendrick, S.; Campbell J. Characterising barrier function among regions of the gastrointestinal tract in Holstein steers. Anim. Prod. Sci. 2014, 54, 1282-1287.

5. Peng, L.; Li, Z.R.; Green, R.S.; Holzman, I.R.; Lin, J. Butyrate Enhances the Intestinal Barrier by Facilitating Tight Junction Assembly via Activation of AMP-Activated Protein Kinase in Caco-2 Cell Monolayers. J. Nutr. 2009, 139, 1619.

6. Beards, E.; Tuohy, K.; Gibson, G. Bacterial, SCFA and gas profiles of a range of food ingredients following in vitro fermentation by human colonic microbiota. Anaerobe 2010, 16, 420-425.

7. Mayo, B.; Van, S.D.; Ventura, M. Genome analysis of food grade lactic Acid-producing bacteria: from basics to applications. Curr. Genomics 2008, 9, 169-183.

8. Brashears, M.M.; Amezquita, A.; Jaroni, D. Lactic acid bacteria and their uses in animal feeding to improve food safety. Adv. Food Nutr. Res. 2005, 50, 1-31

9. Askarian, F.; Kousha, A.; Salma, W.; Ringø, E. The effect of lactic acid bacteria administration on growth, digestive enzyme activity and gut microbiota in Persian sturgeon (Acipenser persicus) and beluga (Huso huso) fry. Aquacult. Nutr. 2011, 17, 488-497.

10. Saki, A.A.; Eftekhari, S.M.; Zamani, P.; Aliarabi, H.; Abbasinezhad, M. Effects of an organic acid mixture and methionine supplements on intestinal morphology, protein and nucleic acids content, microbial population and performance of broiler chickens. Anim. Prod. Sci. 2011, 51, 1025-1033.

11. Brus, M.; Dolinsek, J.; Cencic, A.; Skorhanc, D. Effect of chestnut (Castanea sativa Mill.) wood tannins and organic acids on growth performance and faecal microbiota of pigs from 23 to 127 days of age. Bulg. J. Agr. Sci. 2013, 19, 841-847.

12. Metzler, B.; Bauer, E.; Mosenthin, R. Microflora management in the gastrointestinal tract of piglets. Asian Austral. J. Anim. Sci. 2005, 18, 69-76.

13. Nagaraja, T.G.; Bartley, E.E.; Fina, L.R.; Anthony, H.D. Relationship of rumen gram-negative bacteria and free endotoxin to lactic acidosis in cattle. J. Anim. Sci. 1978, 47, 1329-1337.

14. Edreder, E.A.; Mujtaba, I.M.; Emtir, M. Optimal operation of different types of batch reactive distillation columns used for hydrolysis of methyl lactate to lactic acid. Chem. Eng. J. 2011, 172, 467-475.

15. Liao, M.; Cheng, Q.; Li, Y.H.; Li, B.C.; Yang, S.H.; Ding, B.Y.; Yang, Y.; Yi, D. Effects of Lacti-glyceride on Production Performance,Anti-oxidative Capacity and Energy Metabolism Status of Cold-stressed Broilers. China Poultry 2016, 38, 18-24. 
16. Li, J.L.; Zhang, J.; Qiu, H.Y.; Yang, L.; Tan, L.L.; Ding, B.Y. The effects of tributyrin and trilactin on growth performance, blood biochemical parameters and liver energy status of LPS-challenged broilers. Feed Industry 2014, 35, 38-43.

17. Hou, Y.Q.; Wang, L.; Yi, D.; Ding, B.Y.; Chen, X.; Wang, Q.J.; Zhu, H.L.; Liu, Y.L.; Yin, Y.L.; Gong, J.; Wu, G.Y. Dietary supplementation with tributyrin alleviates intestinal injury in piglets challenged with intrarectal administration of acetic acid. Br. J. Nutr. 2014, 111, 1748-1758.

18. Clarke, R. Cholesterol Fractions and Apolipoproteins as Risk Factors for Heart Disease Mortality in Older Men. Arch. Intern. Med. 2007, 167, 1373-1378.

19. Shepherd, J.; Cobbe, S.M.; Ford, I.; Isles, C.G.; Lorimer, A.R.; MacFarlane, P.W.; McKillop, J.H.; Packard, C.J. Prevention of coronary heart disease with pravastatin in men with hypercholesterolemia. N. Engl. J. Med. 1995, 333, 1301-1307.

20. Gordon, D.J.; Probstfield, J.L.; Garrison, R.J.; Neaton, J.D.; Castelli, W.P.; Knoke, J.D.; Jacobs, D.R.; Bangdiwala, S.; Tyroler, H.A. High-density lipoprotein cholesterol and cardiovascular disease. Four prospective American studies. Circulation 1989, 79, 8-15.

21. Sarfstein, R.; Werner, H. Insulin receptor (InsR) and insulin-like growth factor-I receptor (IGF-GR) translocate to nucleus and regulate IGF-GR gene expression in breast cancer cells. Growth Horm. Igf. Res. 2012, 22, S4-S4.

22. Massoner, P.; Ladurnerrennau, M.; Eder, I.E.; Klocker, H. Insulin-like growth factors and insulin control a multifunctional signalling network of significant importance in cancer. Brit. J. Cancer 2010, 103, 1479.

23. Sato, M.; Tokuji, Y.; Yoneyama, S.; Fujiiakiyama, K.; Kinoshita, M.; Ohnishi, M. Profiling of hepatic gene expression of mice fed with edible japanese mushrooms by DNA microarray analysis: comparison among Pleurotus ostreatus, Grifola frondosa, and Hypsizigus marmoreus. J. Agr. Food Chem. 2011, 59, 10723.

24. Long, Y.; Tsai, W.B.; Wang, D.; Hawke, D.H.; Savaraj, N.; Feun, L.G.; Hung, M.C.; Chen, H.H.; Kuo, M.T. Argininosuccinate synthetase 1 (ASS1) is a common metabolic marker of chemosensitivity for targeted arginine- and glutamine-starvation therapy. Cancer Lett. 2017, 388, 54-63.

25. Shiran, R.; Lital, A.; Keren, Y.; Alona, S.; Alon, S.; Stettner, N.; Sun, Q.; Brandis, A.; Helbling, D.; Korman, S.; Itzkovitz, S.; Dimmock, D.; Ulitsky, I.; Nagamani, S.C.; Ruppin, E.; Erez, A. Diversion of aspartate in ASS1-deficient tumors fosters de novo pyrimidine synthesis. Nature 2015, 527, 379.

26. Sekiya, M.; Osuga, J.; Yahagi, N.; Okazaki, H.; Tamura, Y.; Igarashi, M.; Takase, S.; Harada, K.; Okazaki, S.; Iizuka, Y.; Ohashi, K.; Yagyu, H.; Okazaki, M.; Gotoda, T.; Nagai, R.; Kadowaki, T.; Shimano, H.; Yamada, N.; Ishibashi, S. Hormone-sensitive lipase is involved in hepatic cholesteryl ester hydrolysis. J. Lipid. Res. 2008, 49, 1829-1838.

27. Xue, W.; Wang, W.; Jin, B.; Zhang, X.; Xu, X. Association of the ADRB3, FABP3, LIPE, and LPL gene polymorphisms with pig intramuscular fat content and fatty acid composition. Czech J. Anim. Sci. 2015, 60, 60-66.

28. Jiang, X.C.; Moulin, P.; Quinet, E.; Goldberg, I.J.; Yacoub, L.K.; Agellon, L.B.; Compton, D.; Polokoff, R.S.; Tall, A.R. Mammalian adipose tissue and muscle are major sources of lipid transfer protein mRNA. J. Biol. Chem. 1991, 266, 4631.

29. Borengasser, A.Y.; Varma, V.; Coker, R.H.; Ranganathan, G.; Phanavanh, B.; Rasouli, N.; Kern, P.A. Adipose triglyceride lipase expression in human adipose tissue and muscle. Role in insulin resistance and response to training and pioglitazone. Metabolism 2011, 60, 1012-1020.

30. Asada, K.; Sasaki, S.; Suda, T.; Chida, K.; Nakamura, H. Antiinflammatory roles of peroxisome proliferator-activated receptor gamma in human alveolar macrophages. Am. J. Respir. Crit. Care Med. 2004, $169,195-200$.

31. Jozefczuk, J.; Kashofer, K.; Ummanni, R.; Henjes, F.; Rehman, S.; Geenen, S.; Wruck, W.; Regenbrecht, C.; Daskalaki, A.; Wierling, C.; Turano, P.; Bertini, I.; Korf, U.; Zatloukal, K.; Westerhoff, H.V.; Lehrach, H.; Adjaye, J.A. A Systems Biology Approach to Deciphering the Etiology of Steatosis Employing Patient-Derived Dermal Fibroblasts and iPS Cells. Front. Physiol. 2012, 3, 339.

32. Bailey, A.; Keon, J.; Owen, J.; Hargreaves, J. The ACC1, gene, encoding acetyl-CoA carboxylase, is essential for growth in Ustilago maydis. Mol. Gen. Genet. 1995, 249, 191-201.

33. Hoja, U.; Marthol, S.; Hofmann, J.; Stegner, S.; Schulz, R.; Meier, S.; Greiner, E.; Schweizer, E. HFA1 encoding an organelle-specific acetyl-CoA carboxylase controls mitochondrial fatty acid synthesis in Saccharomyces cerevisiae. J. Biol. Chem. 2004, 279, 21779-21786. 
34. Viñas, G.; Oliveras, G.; Perezbueno, F.; Giro, A.; Blancafort, A.; Puig-Vives, M.; Marcos-Gragera, R.; Dorca, J.; Brunet, J.; Miquel, T.P. Fatty Acid Synthase (FASN) expression in Triple-Negative Breast Cancer. Cancer Res. 2012, 72, 09-11.

35. Muñoz, G.; Ovilo, C.; Noguera, J.L.; Sánchez, A.; Rodríguez, C.; Silió, L. Assignment of the fatty acid synthase (FASN) gene to pig chromosome 12 by physical and linkage mapping. Anim. Genet. 2003, 34, 234-235.

36. Wang, T.; Liu, C.; Xiong, Y.Z.; Deng, C.Y.; Zuo, B.; Xie, H.T.; Xu, D.Q. Isolation and Cloning of Porcine SLC27A2 Gene and Detection of Its Polymorphism Associated with Growth and Carcass Traits. Asian Austral. J. Anim. Sci. 2007, 20, 1169-1173.

37. Hou, Y.Q.; Wang, L.; Zhang, W.; Yang, Z.G.; Ding, B.Y.; Zhu, H.L.; Liu, Y.L.; Qiu, Y.S.; Yin, Y.L.; Wu, G.Y. Protective effects of $\mathrm{N}$-acetylcysteine on intestinal functions of piglets challenged with lipopolysaccharide. Amino Acids 2012, 43, 1233-1242.

38. Hou, Y.Q.; Wang, L.; Yi, D.; Ding, B.Y.; Liu, Y.L.; Zhu, H.L.; Liu, J.; Li, Y.T.; Wu, X.; Yin, Y.L.; Wu, G.Y. Dietary $\alpha$-ketoglutarate supplementation ameliorates intestinal injury in lipopolysaccharide-challenged piglets. Amino acids 2010, 29, 555-564.

39. Mansoori, B.; Nodeh, H.; Modirsanei, M.; Rahbari, S.; Aparnak, P. D-Xylose absorption test: A tool for the assessment of the effect of anticoccidials on the intestinal absorptive capacity of broilers during experimental coccidiosis. Anim. Feed Sci. Tech. 2009, 148, 301-308.

40. Yang, M.; Gao, F.; Liu, H.; Yu, W.H.; Zhuo, F.; Qiu, G.P.; Ran, J.H.; Sun, S.Q. Hyperosmotic induction of aquaporin expression in rat astrocytes through a different MAPK pathway. J. Cell Biochem. 2013, 114, 111-119.

41. Suzuki, M.; Tanaka, S. Molecular and cellular regulation of water homeostasis in anuran amphibians by aquaporins. Comp. Biochem. Phys. A 2009, 153, 231-241.

42. Chan, J.Y.; Kwong, M. Impaired expression of glutathione synthetic enzyme genes in mice with targeted deletion of the Nrf2 basic-leucine zipper protein. BBA Biomembranes 2000, 1517, 19.

43. Zhu, J.; Bi, Z.; Yang, T.; Wang, W.; Li, Z.; Huang, W.; Wang, L.; Zhang, S.; Zhou, Y.; Fan, N.; Bai, Y.E.; Song, W.; Wang, C.; Wang, H.; Bi, Y. Regulation of PKM2 and Nrf2-ARE Pathway during Benzoquinone Induced Oxidative Stress in Yolk Sac Hematopoietic Stem Cells. Plos One 2014, 9, e113733.

44. Peterson, J.R.; Burmeister, M.A.; Tian, X.; Zhou, Y.; Guruju, M.R.; Stupinski, J.A.; Sharma, R.V.; Davisson, R.L. Genetic silencing of Nox2 and Nox4 reveals differential roles of these NADPH oxidase homologues in the vasopressor and dipsogenic effects of brain angiotensin-II. Hypertension 2009, 54, 1106.

45. Masoudi, M.; Saadat, M. Arsenic, GSTO2 Asp142 polymorphism, health and treatment. Excli. J. 2008, 7, 115-118.

46. Tsukita, S.; Furuse, M. The structure and function of claudins, cell adhesion molecules at tight junctions. Ann NY Acad Sci 2000, 915, 129-135.

47. Schneeberger, E.E.; Lynch, R.D. The tight junction: a multifunctional complex. Am. J. Physiol. Cell Physiol. 2004, 286, 1213-1228.

48. Moll, R.; Robine, S.; Dudouet, B.; Louvard, D. Villin: a cytoskeletal protein and a differentiation marker expressed in some human adenocarcinomas. Virchows. Arch. B 1987, 54, 155-169.

49. Wang, Y.; Srinivasan, K.; Siddiqui, M.R.; George, S.P.; Tomar, A.; Khurana, S. A novel role for villin in intestinal epithelial cell survival and homeostasis. J. Biol. Chem. 2008, 283, 9454-9464.

50. Jänicke, R.U.; Sprengart, M.L.; Wati, M.R.; Porter, A.G. Caspase-3 is required for DNA fragmentation and morphological changes associated with apoptosis. J. Biol. Chem. 1998, 273, 9357-9360.

51. Pedersen, R.; Andersen, A.D.; Molbak, L.; Stagsted, J.; Boye, M. Changes in the gut microbiota of cloned and non-cloned control pigs during development of obesity: Gut microbiota during development of obesity in cloned pigs. BMC Microbiol. 2013, 13, 30.

52. Ramadan, Z.; Xu, H.; Laflamme, D.; Czarnecki-Maulden, G.; Li, Q.J.; Labuda, J.; Bourqui, B. Fecal Microbiota of Cats with Naturally Occurring Chronic Diarrhea Assessed Using 16S rRNAGene 454-Pyrosequencing before and after Dietary Treatment. J. Vet. Int. Med. 2014, 28, 59-65.

53. Kang, D.W.; Park, J.G.; Ilhan, Z.E.; Wallstrom, G.; LaBaer, J.; Adams, J.B.; Krajmalnik-Brown, R. Reduced incidence of Prevotella and other fermenters in intestinal microflora of autistic children. Plos One 2013, 8, e68322. 
54. Wu, G.D.; Chen, J.; Hoffmann, C.; Bittinger, K.; Chen, Y.Y.; Keilbaugh, S.A.; Bewtra, M.; Knights, D.; Walters, W.A.; Knight, R.; et al. Linking longterm dietary patterns with gut microbial enterotypes. Science 2011, 333, 105-108.

55. Sabine, G.; Sabine, W.; Alla, L.; Goegelel, H.; Sifri, C.D.; Martin, K.; Hinder, R.; Nguyen, J.H. Complete genome sequence of Veillonella parvula type strain (Te3). Stand. Genom. Sci. 2010, 2, 57-65.

56. Biddle, A.; Stewart, L.; Blanchard, J.; Leschine, S. Untangling the Genetic Basis of Fibrolytic Specialization by Lachnospiraceae and Ruminococcaceae in Diverse Gut Communities. Diversity 2013, 5, 627-640.

57. Shang, Q.; Shan, X.; Cai, C.; Hao, J.; Li, G.; Yu, G. Dietary fucoidan modulates the gut microbiota in mice by increasing the abundance of Lactobacillus and Ruminococcaceae. Food Funct. 2016, 7, 3224-3232.

58. Kang, P.; Xiao, H.L.; Hou, Y.Q.; Ding, B.Y.; Liu, Y.L.; Zhu, H.L.; Hu, Q.Z.; Hu, Y.; Yin, Y.L. Effects of astragalus polysaccharides, achyranthes bidentata polysaccharides, and acantbepanax senticosus saponin on the performance and immunity in weaned pigs. Asian Austral. J. Anim. 2010, 23, 750.

59. Tan, B.E.; Yin, Y.L.; Liu, Z.Q.; Li, X.G.; Xu, H.J.; Kong, X.F.; Huang, R.L.; Tang, W.J.; Shinzato, I.; Smith, S.B.; Wu, G.Y. Dietary L-arginine supplementation increases muscle gain and reduces body fat mass in growing-finishing pigs. Amino Acids 2009, 37, 169-175.

60. Wang, L.; Hou, Y.Q.; Yi, D.; Ding, B.Y.; Zhao, D.; Wang, Z.; Zhu, H.L.; Liu, Y.L.; Gong, J.; Assaad, H.; Wu, G.Y. Beneficial roles of dietary oleum cinnamomi in alleviating intestinal injury. Front Biosci 2014, 20, 814-828.

61. Dan, Y.; Hou, Y.Q.; Wang, L.; Zhao, D.; Ding, B.Y.; Wu, T.; Chen, H.B.; Liu, Y.L.; Kang, P.; Wu, G.Y. Gene expression profiles in the intestine of lipopolysaccharide-challenged piglets. Front. Biosci. 2016, 21, 487-501.

62. Yao, K.; Yin, Y.L.; Chu, W.; Liu, Z.; Deng, D.; Li, T.; Huang, R.; Zhang, J.; Tan, B.E.; Wang, W.; Wu, G.Y. Dietary arginine supplementation increases mtor signaling activity in skeletal muscle of neonatal pigs. $J$. Nutr. 2008, 138, 867-872.

63. Caporaso, J.G.; Kuczynski, J.; Stombaugh, J.; Bittinger, K.; Bushman, F.D.; Costello, E.K.; Fierer, N.; Peña, A.G.; Goodrich, J.K.; Gordon, J.I.; et al. QIIME allows analysis of high-throughput community sequencing data. Nat. Methods 2010, 7, 335-336.

64. Lozupone, C.; Knight, R. UniFrac: A new phylogenetic method for comparing microbial communities. Appl. Environ. Microbiol. 2005, 71, 8228-8235.

65. Price, M.N.; Dehal, P.S.; Arkin, A.P. FastTree: Computing large minimum evolution trees with profiles instead of a distance matrix. Mol. Biol. Evol. 2009, 26, 1641-1650. 
16 of 16

570 67. Author 1, A.B. Title of Thesis. Level of Thesis, Degree-Granting University, Location of University, Date of $571 \quad$ Completion.

572 68. Title of Site. Available online: URL (accessed on Day Month Year). 